\title{
Animals, autopsies and artefacts
}

\author{
Roger W. Byard
}

Accepted: 16 July 2011/Published online: 29 July 2011

(C) Springer Science+Business Media, LLC 2011

In the last issue of Forensic Science, Medicine and Pathology Buschmann et al. [1] described decapitation associated with postmortem dog attacks. While drawing attention to a specific form of craniocerebral trauma, the paper also raises the issue of difficulties that may arise in assessing the significance of injuries inflicted by animals, as not infrequently autopsies are conducted on bodies with features that have been modified by animal activity. While the sequence of events leading up to, and following, the fatal episode is usually not difficult to establish, on occasion the precise role played by the injuries may be difficult to determine. Ascertaining whether injuries from animal attacks occurred before or after death, contributed to the death, were incidental to the death, or merely modified underlying diseases or other injuries are issues that may need to be addressed [2].

Deaths from animal attacks may be caused by a wide variety of mechanisms involving blunt and sharp trauma, crushing, envenomation, anaphylaxis or sepsis [3-5]. Blunt trauma from animals has been confused with homicide [6] and careful scene evaluations may need to be conducted to exclude human activity. However, attacks may either have been witnessed, or the proximity of offending animals to victims and previous behaviour may be clues to their involvement. Difficulties may arise when there is no evidence at autopsy of significant trauma as may occur, for example, with an anaphylactic death. The absence of stings does not exclude bee or wasp attack and ancillary studies, including serum tryptase and specific IgE levels, will need

\section{R. W. Byard $(\bowtie)$}

Discipline of Anatomy and Pathology, Level 3 Medical School North Building, The University of Adelaide, Frome Rd,

Adelaide, SA 5005, Australia

e-mail: roger.byard@sa.gov.au to be undertaken. Similarly, victims of snake bite may not have readily apparent bite marks at autopsy [4]. Those who are immunocompromised may also succumb to unusual infections following apparently innocuous animal bites [7]. Antemortem dog attacks may produce similar injuries to those arising from postmortem feeding and in the event of a suspected fatal attack examination and/or necropsy of the animal may be required. Specific guidelines on the handling of such cases have been published [8, 9].

Postmortem injuries may be species-specific related to animal size and morphology. For example sea lice tend to burrow through soft tissues under the skin creating oval defects in the overlying epidermis whereas sharks will remove large pieces of tissue, organs or entire limbs. Animals will also concentrate on body orifices or defects, and so wound characteristics may be extensively modified by many animals ranging from fly larvae (maggots) to cats and dogs. Trauma to the genitalia or anogenital region by carnivores may raise the suspicion of a sadistic sexual assault and homicide with mutilation. Given the predilection of carnivores, such as domestic dogs, for wound sites, the possibility of ingestion of projectiles from shooting deaths must be considered, with examination and X-ray of the animal and/or feces collected from the scene.

Certain individuals have an increased likelihood of postmortem animal mutilation and this applies particularly to elderly recluses who may share their homes with a variety of domestic (e.g. dogs and cats) and feral animals (e.g. rats and mice). Referred to as the Diogenes syndrome, there may be great difficulties for the police and pathologist in evaluating cases as underlying alcoholism or significant illnesses may have resulted in falls with bruising. This, added to the general state of disarray of such households, may suggest assault with robbery [10]. Individuals who may have been unconscious for some time may have been 
attacked while alive and may have a vital tissue reaction at the site of animal bites, the so-called Popiel phenomenon (named after a legendary Polish king who was devoured alive by rats) [11].

While post-mortem injuries to bodies from animals are usually completely incidental to the cause and manner of death, perpetrators have sometimes attempted to disguise homicides by feeding the remains of victims to animals [12]. Removal of tissues may also prevent accurate establishment of the cause of death and sometimes determination of whether an injury contributed to or followed death will simply not be possible. An example of this would be a body recovered from the sea with shark bites-whether the victim drowned and was then eaten, or was attacked while alive, will usually not be determinable if the event was not witnessed, particularly if there is some degree of putrefactive overlay.

Injuries caused by animals during life may, therefore, be quite subtle but have far reaching consequences, and postmortem damage can significantly impair the pathological assessment of bodies. Adequate training in forensic pathology requires familiarity with the types of artefacts that may be introduced by predatory animals, and when evidence of animal activity is found at autopsy consideration of a wide range of possibilities is required.

\section{References}

1. Buschmann C, Solarino B, Püschel K, Czubaiko F, Heinze S, Tsokos M. Post-mortem decapitation by domestic dogs: three case reports and review of the literature. Forensic Sci Med Pathol. 2011; doi:10.1007/s12024-011-9233-x.

2. Byard RW, James RA, Gilbert JD. Diagnostic problems associated with cadaveric trauma from animal activity. Am J Forensic Med Pathol. 2002;23:238-44.

3. Bury D, Langlois NEI, Byard RW. Animal-related fatalities Part I: characteristic autopsy findings and variable causes of death associated with blunt and sharp trauma. J Forensic Sci. (in press).

4. Bury D, Langlois NEI, Byard RW. Animal-related fatalities Part II: characteristic autopsy findings and variable causes of death associated with envenomation, poisoning, anaphylaxis, asphyxiation and sepsis. J Forensic Sci. (in press).

5. Langley RL. Animal-related fatalities in the United States-an update. Wilderness Environ Med. 2005;16(2):67-74.

6. Murray LA, Sivaloganathan S. Rambutt-the killer sheep. Med Sci Law. 1987;27:95-7.

7. Stiegler D, Gilbert JD, Warner MS, Byard RW. Fatal dog bite in the absence of significant trauma-Capnocytophaga canimorsus infection and unexpected death. Am J Forensic Med Pathol. 2010;31:198-9.

8. Tsokos M, Byard RW, Püschel K. Extensive and mutilating craniofacial trauma involving defleshing and decapitation. Unusual features of fatal dog attack in the young. Am J Forens Med Pathol. 2007;28:131-6.

9. Sacks JJ, Lockwood R, Hornreich J, Sattin RW. Fatal dog attacks, 1989-1994. Pediatrics. 1996;97:891-5.

10. Byard RW, Gilbert JD, Tsokos M. Forensic issues in cases of Diogenes syndrome. Am J Forensic Med Pathol. 2007;28:177-81.

11. Koszyca B, Gilbert JD, Byard RW. Antemortem trauma from rodent activity. The Popiel phenomenon. Forensic Sci Med Pathol. 2006;2:269-72.

12. Boglioli LR, Taff ML, Turkel SJ, Taylor JV, Peterson CD. Unusual infant death. Dog attack or postmortem mutilation after child abuse? Am J Forens Med Pathol. 2000;21:389-94. 